\title{
THE DETERMINATION OF THE RELATIVE VOLUMES OF THE COMPONENTS OF ROCKS BY MENSURATION METHODS.
}

Francis Church Lincoln and Henry Lewis Rietz.

I. GENERAL CONSIDERATIONS.

A determination of the relative volumes of the components of a rock may have for its object description, nomenclature, computation of chemical composition, estimation of desirable or undesirable mineral content, or comparison. A quantitative statement of the mineralogical composition of a rock is essential to a good description. While the mineralogical classification of rocks is not on a strictly quantitative basis, yet some estimate of the relative proportions of components, if only a rough one, is necessary before a rock can be named. Chemical nomenclature and chemical composition may be more directly obtained from chemical analysis. The commercial importance of determining directly the proportion of a valuable or harmful mineral is self-evident; and comparisons of mineral compositions of rocks may also have considerable economic value.

This is especially true in metal mining and in quarrying stone. Owing to the intimate relationship frequently existing between ore deposits and country rocks, a mineralogical comparison of the rocks in a mining district is frequently of value. A good example of a comparative study of this nature is presented by Barrell in his "Microscopical Petrography of the Elkhorn Mining District, Jefferson County, Montana." 1 The relative quantities of the components of building and ornamental stones affect their properties and render comparative studies desirable. A good example of such a study is Dale's "The Chief Commercial Granites of Massachusetts, New Hampshire and Rhode Island."2

${ }^{1}$ a2nd Ann. Rep. U. S. Geol. Sur., Part II. (I90r), 5II-549.

${ }^{2}$ U. S. Geol. Sur. Bull. 354 (Igo8). 
In the two works just cited, methods dependent on measurements were employed to determine the relative amounts of the components of the rocks. Such methods may well be termed "mensuration" methods; and other methods which might have been used and are dependent on chemical analyses and specific gravity manipulations may be called "chemical" and "density" methods respectively. These latter methods may be subdivided into " simple" and "complex," according as they require a single analysis or manipulation, or several; while the former methods may be subdivided into "areal" and "linear" according as they call for the measurement of areas or of lines. The proposed classification is as follows :

$$
\begin{array}{ll}
\text { Mensuration: } & \left\{\begin{array}{l}
\text { Simple, } \\
\text { Complex. }
\end{array}\right. \\
\text { Density: } & \left\{\begin{array}{l}
\text { Simple, } \\
\text { Complex. }
\end{array}\right. \\
\text { Chemical: } & \left\{\begin{array}{l}
\text { Areal, } \\
\text { Linear. }
\end{array}\right.
\end{array}
$$

Before taking up the details of the mensuration methods, it seems advisable to outline briefly and to compare all methods. The chemical methods destroy the mineral components by solution at the outset and never afterward deal with them directly; the density methods deal with the components in volumes; and the mensuration methods deal with them in areas or in intercepts.

The simple chemical method consists in making a chemical analysis of the rock and computing the chemical constitutents to mineral components. This method is not only indirect, but it also calls for expert chemical manipulation. There are four cases in which it cannot be applied: (I) when two minerals of the same composition occur in the rock, (2) when two minerals are present whose combination in any proportion might produce a third mineral which also exists in the rock, (3) when minerals whose composition is variable are involved, and (4) when a mineral of unknown composition is a component. In the first 
two cases, the chemical methods fail completely, but in the last two the complex chemical method may be employed.

The complex chemical method consists in obtaining an analysis of the rock as in the simple method and supplementing it by analyses of the variable or unknown minerals present. It is open to the same objections as the simple method and has the additional disadvantages that it is difficult to separate the rock constituents to obtain the material for the supplementary analyses, and that it consumes a very considerable amount of time. It should be noted that a very close approximation can be made in the case of variable minerals without resort to the complex method, since it has been shown that variable minerals have similar compositions in similar rocks. Published analyses of variable minerals in similar rocks may thus be substituted in place of actual analyses without occasioning large errors.

The simple density method consists in computing the mineral components of a rock from a specific gravity determination. It is only applicable to rocks consisting of two minerals of different specific gravities. It is simple, direct and extremely rapid, but since most rocks contain more than two minerals its application is very limited.

The complex density method is more widely applicable. It consists in crushing a sample of rock, separating the fragments into groups according to specific gravities by means of heavy solutions, and computing the relative proportions of components from the amount in each group. Although a direct method, the objections to this procedure are much more serious than those to the indirect chemical methods. No matter to what degree of fineness the crushing is carried, it never completely detaches the mineral particles from one another. Even if equal quantities of minerals clung to each other, as might happen in rare instances, the results would be invalidated in the case of a rock consisting of more than two minerals, - the only rock requiring the complex process,- - because particles of minerals of higher and lower densities when attached to one another would sink in a heavy solution with pure grains of intermediate density. Fine crush- 
ing reduces this error but introduces another by producing a quantity of dust so fine that it will not settle in water,-much less in heavy solutions. This material is only proportional to the minerals present in those rare instances when all of these minerals are of the same degree of brittleness. In most cases, it contains a higher proportion of the more brittle minerals in the rock than does the coarser portion, and its removal before the heavy solution treatment vitiates the results. It is apparent that this method calls for considerable manipulative skill. It fails completely when minerals of the same specific gravity occur in the rock.

In the mensuration methods, the areas or intercepts of the mineral components, recognized by their optical properties, are estimated or measured directly, and the percentages computed from their sums. The mensuration methods have the advantage over the chemical methods that they are less liable to error since they measure the rock components directly; over the simple density method that they have a more general application; and over the complex density method that they are more reliable since free from its innate limitations. Over both chemical and density methods they have two obvious advantages-they require no expert manipulation other than petrographical, and the samples employed remain intact for future reference and study.

\section{DESCRIPTION OF MENSURATION METHODS.}

The estimation of the proportions of minerals in a rock by the examination of specimens or exposures is dependent upon mental measurements of the comparative areas of the minerals viewed and is properly an areal mensuration method. This is the commonest of all mensuration methods and was undoubtedly the first to be employed.

A real estimation may also be used in microscopy. Barrell describes the procedure in the following words:

"The field of the microscope is divided into quadrants by the cross hairs, and these are mentally divided into sectors which are thirds, fifths or smaller fractions. By taking such a power of objective that the component to be estimated is represented in the field of view by a fair num- 
her of crystals, the latter can be mentally collected together and packed in one quadrant, and the fraction which it fills estimated.".1

The first mensuration method to make use of physical measurements was the areal method of Delesse. ${ }^{2}$ He applied a transparent sheet of paper or goldbeaters' skin to the polished or nearly plane surface of a rock and traced upon it the outlines of the various mineral grains. The sketch was then tinted so that the various minerals might be distinguished, and the sheet pasted with soluble gum to a piece of tin foil. The variously tinted surfaces with their adhering tin foil were next cut apart and grouped according to their colors, the paper washed away, the tin foil particles in each group weighed, and the percentages of the various mineral components of the rock computed directly from these weights.

Sorby $^{3}$ extended this method to microscopy, and at the same time eliminated the complicated tin foil procedure into which Delesse had been forced on account of the character of the paper he employed. Sorby says :

"In order to know the relative bulk of the constituents, whether organic or mineral, I select a portion of the object that shows the general character in a satisfactory manner, and draw on an evenly thick piece of drawing-paper the outline of the various: portions with a camera lucida, distinguishing by some mark the different constituents. I then weigh the whole in accurate balances and afterwards cut out the various portions and weigh them."

Julien $^{4}$ used microphotographs, cutting them up and weighing the fragments just as Sorby did his camera lucida sketches

Williams ${ }^{5}$ measured the areas of the grains directly by means of an eyepiece micrometer cross-ruled into squares. The squares which came within the boundaries of each particle were counted, and from the measurements obtained the relative volumes of the various minerals were computed.

${ }^{1} \mathrm{Op}$. cit., p. $5 \mathrm{I} 3$.

${ }^{2}$ Comptes Rendus, 25 ( 1847 ), 544-545.

${ }^{3}$ Philosophical Mag., II (1856), 21.

${ }^{4}$ Bull. Geol. Soc. of Am., I4 (1903), 466.

'Am. Geol., 35 (1905), 44. 
Lincoln has found the measurement of areas with a planimeter very satisfactory. The planimeter may be used upon a camera lucida drawing, a photograph, an illustration, or directly upon the surface of a coarse-grained rock. As in Williams' method, the areas are obtained without recourse to weighing, thus eliminating one source of error and saving time, while the use of the planimeter is far less trying to the eyes than that of the crossruled micrometer. Furthermore, the planimeter method has the advantage that it may be used upon a valuable sketch or photograph or upon a figure in a book without injury to the subject.

The linear mensuration method was devised by Rosiwal. ${ }^{1}$ It consists in measuring the intercepted lengths of grains along a line or series of lines and calculating the percentages by volume by dividing the total distance measured into the sum of the intercepts for each component. As Rosiwal expresses it:

"In place of Delesse's leaf of rock we have a thread of rock, an exceptionally slender prism whose volume is comparable to the extremely slender core of a borehole of the smallest possible dimensions."

If the mineral particles are of large size, the intercepts may be measured directly upon a smooth face with the aid of a pair of dividers and a scale. The measurements may follow a ruled line or an imaginary one. A convenient method in the case of a small specimen is to stretch an elastic about it and to measure the intercepts along the upper edge of the rubber band. In this way, none of the minerals are obscured, and if it happens that a grain barely extends beyond the elastic, the band may be temporarily pushed aside while the mineral is being identified.

When the linear method is used microscopically, thin lines are ruled in ink across the cover glass of the thin section. Such lines are semi-transparent; and if they do interfere with the identification of a mineral at any point, may be readily erased at that spot. The measurements along these lines are conveniently made with an eyepiece micrometer.

${ }^{1}$ Verh. der k. k. geol. Reichsanstalt (1898), 143-175. 
III. THEORY.

Delesse $^{1}$ outlined a proof by calculus that the sums of the areas of the components on a plane surface of a rock are proportional to the volumes of the components in the rock. Rosiwal ${ }^{2}$ extended this form of proof to show that intercepts on lines are also proportional to volumes. Despite these proofs, Julien ${ }^{3}$ and Williams ${ }^{4}$ hold that the results obtained by mensuration methods are not directly proportional to volumes, but rather to diameters or squares of diameters, and that the shapes of the individual mineral grains play an important part and must be taken into consideration in the calculations. Since the theory of the mensuration methods has thus been called into question, the following alternate geometrical proof is presented.

According to Cavalieri's theorem, "Two solids lying between two parallel planes, and such that the two sections made by any plane parallel to the given planes are equal, are themselves equal."s Then two solids lying between two parallel planes, and such that the two sections made by any plane parallel to the given planes have a constant ratio, have themselves that same ratio. For if the ratio were $a: b$, then the first solid might be formed from $a$ equal Cavalieri bodies and the second solid from $b$ of the same solids, when the ratio of the volumes of the solids would be $a: b$. Furthermore, two groups of solids lying between two parallel planes, and such that the sums of the sections of the two groups made by any plane parallel to the given planes have a constant ratio, have themselves that same ratio. For these groups might be formed by cutting up the solids previously considered, and moving the fragments parallel to the given planes, when the ratios would not be disturbed. Finally, since any number of groups may be considered two at a time, (I.) Groups of solids lying between two parallel planes, and such that the sums of the sections of the groups made by any plane parallel to the given planes have a constant ratio, have themselves that same ratio.

${ }^{1}$ Annales des Mines, Series IV., I3 (1848), 380-383.

${ }^{2} O p$. cit., pp. I46-147.

${ }^{3}$ Bull. Geol. Soc. of Am., 14 (I903), 460.

Am. Geol., 35 (1905), 40-46.

"Beman and Smith, "New Plane and Solid Geometry" (I900), 358. 
Stated for plane surfaces, this becomes: (II.) Groups of plane areas lying between two parallel lines, and such that the sums of the intercepts of the groups made by any line parallel to the given lines have a constant ratio, have themselves that same ratio.

Now let us consider the case of a rock composed of mineral particles thoroughly mixed so that the laws of chance come into play. If a number of parallel lines are drawn in any plane in this rock, they will intercept grains of the different minerals in ratios which will show less fluctuation the longer the lines. By taking a sufficient length for these lines, the ratios may be made constant to any desired degree of accuracy. It follows from proposition $I I$., that in the case of a rock composed of well-mixed grains, the sums of the intersected lengths of mineral particles along a sufficiently protracted line are proportional to their areas.

Let us next consider a number of parallel planes passed through this same rock. They will make sections of the different sorts of mineral grains the ratios of whose sums will vary less the greater the areas of the planes. If these planes are taken large enough so that these fluctuations become negligible, then from proposition $I$., the sums of the sections of the mineral particles will be proportional to their volumes.

Finally, it follows that if a plane is taken of sufficient extent so that any line in it will intercept lengths of minerals proportional to areas of sections, such plane will also make sections of minerals proportional to their volumes, and thus the sums of intercepted lengths will be proportional not only to areas but also to volumes.

IV. REQUISITE NUMBER OF MEASUREMENTS.

A. Statement of Rosizeral.-Having assured ourselves that the theory of the mensuration methods is sound, we naturally inquire next as to the number of mineral particles to be measured in order reasonably to expect a desired degree of accuracy in the derived precentage of the volume. In discussing this question of accuracy, we shall confine ourselves to the linear mensuration method of Rosiwal because it is the simplest method and the one most readily applied. 
Rosiwal says:

"It is easily seen that the degree of accuracy must be directly proportional to the length of the indicatrice selected for measurement and inversely proportional to the size of the grains of the rock. Under the assumption of greatest possible regularity of distribution and size of grains of the component minerals of the rock, we must select a length of indicatrice equal to at least one hundred times the size of the grains to obtain an accuracy of measurement of approximately $I$ per cent.; and, with not unexceptionable regularity of distribution, must surely measure several indicatrices lying in different planes of a parallelopiped (cube)."1

That roo measurements is insufficient under ordinary conditions to lead us reasonably to expect an accuracy of I per cent., is clear from Rosiwal's own sketch and measurements of a quartzbiotite-diorite from Pozar, Bohemia. ${ }^{2}$ We estimate that 204 intercepts were measured in one direction upon this specimen and 215 intercepts in a direction at right angles to this. The percentages of quartz, feldspar, and biotite computed from these two sets of measurements deviate by 1.5 per cent., 3.6 per cent., and I.6 per cent. respectively. Moreover, by thus measuring across the same surface in two directions, the full effect of random sampling can hardly be attained, and results so secured may reasonably be expected to show smaller deviations than would have been obtained by the measurement of two distinct random samples of the same rock.

Rosiwal's minimal requirement does not, therefore, give us even a general idea as to the number of grains that should be measured to secure a desired degree of accuracy, and his valuable article contains no other statements which have a direct bearing on this point.

B. Algebraic Formulation of the Problem:-Two kinds of errors may enter into this problem-those due to incorrect measurements and those due to chance fluctuations in the material measured. The first class of errors is of but slight importance in the present problem and will not be specially considered. The

${ }^{1}$ Op. cit., p. 148.

2 Ibid., pp. I59 and I6r. 
second class of errors is due to the element of chance introduced when we consider the grains of a mineral which will be intercepted by a random line run through a rock, and is of prime importance in our problem.

Let us assume that the mineral particles in a rock are so thoroughly mixed that the laws of chance come into play. We may then depend upon a random sample for the determination of the percentages of the various components, and any subsequent determination from a similar random sample will manifest fluctuations whose character will be in conformance with the laws of random sampling. The problem is to determine approximately the number of grains, $n$, whose intercepts should be measured so that, under the theory of random sampling, we may reasonably expect that the error in the ratio, $p$, of the volume of a certain mineral, $A$, to the total volume of the rock shall not exceed a certain percentage, $E$. Let the individual intercepts of $A$ be $x_{1}$, $x_{2}, \ldots x_{n}$ and the arithmetical mean of these intercepts be $\bar{x}$. Also let $\sigma_{x}$ be the standard deviation of these intercepts, that is, the square root of the arithmetical mean of the squares of the deviations of the individual intercepts from their arithmetical mean. Then

$$
\bar{x}=\frac{x_{1}+x_{2}+\cdots+x_{n}}{n}
$$

and

$$
\sigma_{x}=\sqrt{\frac{\left(x_{1}-\bar{x}\right)^{2}+\left(x_{2}-\bar{x}\right)^{2}+\cdots+\left(x_{n}-\bar{x}\right)^{2}}{n}} .
$$

Now let $y_{1}, y_{2}, \ldots, y_{n}$ be the intercepts of the spaces between the grains of $A, y$ their arithmetical mean, and $\sigma_{y}$ their standard deviation. Then

and

$$
\bar{y}=\frac{y_{1}+y_{2}+\cdots+y_{n}}{n}
$$

$$
\sigma_{y}=\sqrt{\frac{\left(y_{1}-\bar{y}\right)^{2}+\left(y_{2}-\bar{y}\right)^{2}+\cdots+\left(y_{n}-\bar{y}\right)^{2}}{n}}
$$


and

$$
p=\frac{n \bar{x}}{n \bar{x}+n \bar{y}}=\frac{\bar{x}}{\bar{x}+\bar{y}} .
$$

Next let $\delta p$ be the change from the most probable value of $p$ to be expected in taking samples. Then

$$
\delta p=\frac{\bar{y} \delta \bar{x}-\bar{x} \delta \bar{y}}{(\bar{x}+\bar{y})^{2}}
$$

and

$$
\overline{\delta p^{2}}=\frac{\bar{y}^{2}(\delta \bar{x})^{2}+\bar{x}^{2}(\delta \bar{y})^{2}-2 \overline{x y} \delta \bar{x} \delta \bar{y}}{(\bar{x}+\bar{y})^{4}} .
$$

Summing up the $\delta p^{2}$ 's for the different samples and dividing by the number of samples, the square of the standard deviation of $p$ is obtained. Let $\sigma_{p}$ be the standard deviation of $p$. Then, if $x$ and $y$ are uncorrelated, we have by summation of $(7)$, to correspond to any number of repetitions:

$$
\sigma_{p}^{2}=\frac{\bar{y}^{2}{\sigma_{\bar{x}}}^{2}+\bar{x}^{2}{\sigma_{\bar{y}}^{2}}^{2}}{(\bar{x}+\bar{y})^{4}} .
$$

And since ${\sigma_{\bar{x}}}^{2}=\sigma_{x}^{2} / n$, and ${\sigma_{\bar{y}}}^{2}=\sigma_{y}{ }^{2} / n$

$$
\sigma_{p}^{2}=\frac{\bar{y}^{2}{\sigma_{\bar{x}}}^{2}+\bar{x}^{2}{\sigma_{\bar{y}}^{2}}^{2}}{n(\bar{x}+\bar{y})^{4}}
$$

and

$$
n=\frac{\bar{y}^{2} \sigma_{x}^{2}+\bar{x}^{2} \sigma_{y}^{2}}{\sigma_{p}{ }^{2}(\bar{x}+\bar{y})^{4}} .
$$

The probable error in a determination is an amount such that there is an even chance that if a similar determination be made from a second random sample it will deviate from the first by more or by less than that amount. The probable error of a single determination is 0.6745 times its standard deviation. So the probable error of $p$ is $0.6745^{a_{p}}$

If we are willing that a determination of $p$ shall have a probable error of I per cent., then we shall have

$$
\begin{aligned}
0.6745^{\sigma_{p}} & =0 . \mathrm{OI}, \\
\sigma_{p} & =0.01482,
\end{aligned}
$$


and with $\sigma_{p}=0.01482$, (I0) becomes:

$$
n=4550 \frac{\bar{y} \sigma_{x}^{2}+\bar{x} \sigma_{y}^{2}}{(\bar{x}+\bar{y})^{4}} \text { (approximately) }
$$

The employment of the probable error in this manner ensures only an even chance that a second similar determination will check within $E$ per cent. If twice the probable error be used in obtaining a formula for $n$, the chances are 4.5 to I that a second determination will not vary by more than $E$ per cent.; if three times, the chances are $2 \mathrm{I}$ to I ; and if 4 times, I42 to I. We may therefore feel reasonably sure that the deviation will not exceed $E$ per cent. if we make use of 3 or 4 times the probable error in deducing our formula. Now in obtaining the formula for $n$ the probable error is squared, so to obtain such a value for $n$ that we may reasonably expect a second determination of $p$ to check within I per cent. we must multiply (I2) by some number from 9 to 16 , or say at least Io, giving

$$
n=45,500 \frac{\bar{y} \sigma_{x}{ }^{2}+\bar{x} \sigma_{y}{ }^{2}}{(\bar{x}+\bar{y})^{4}} .
$$

C. Solution of Problem for a Maine Granite by Intercept Method.-In order to form a definite idea of the number required in an actual case, we measured the intercepts along ten parallel lines on a polished specimen of biotite-granite from Maine. The components of this rock are glassy quartz, pink orthoclase, milky white oligoclase, and black biotite, fairly well mixed but showing some tendency to segregation. The intercepts were measured macroscopically with a pair of dividers and a scale ruled in hundredths of an inch.

The frequency distributions of the measurements of intercepts of grains and of spaces between grains for each mineral are presented in Table I. There also will be found the arithmetical means and standard deviations calculated by the short and accurate method of Davenport and Rietz. ${ }^{1}$ A study of the correlation of $x$ 's and $y$ 's for quartz shows that correlation is absent, even between successive $x$ 's and $y$ 's, and thus makes it certain

${ }^{1}$ Bull. Agric. Exp. Sta. Univ. of Ill., IIg (I909), 9-II. 
TABLE I.

Frequency Distributions of Measurements of Maine Granitf.

\begin{tabular}{|c|c|c|c|c|c|c|c|c|}
\hline \multirow{3}{*}{$\begin{array}{l}\text { Length in Hun- } \\
\text { dredths of an } \\
\text { Inch. }\end{array}$} & \multicolumn{8}{|c|}{ Number of Measurements. } \\
\hline & \multicolumn{4}{|c|}{ On Grains of: } & \multicolumn{4}{|c|}{ On Spaces between: } \\
\hline & Quartz. & $\begin{array}{l}\text { Ortho- } \\
\text { clase. }\end{array}$ & $\begin{array}{l}\text { Oligo- } \\
\text { clase. }\end{array}$ & Biotite. & Quartz. & $\begin{array}{l}\text { Ortho- } \\
\text { clase. }\end{array}$ & Oligoclase. & Biotite. \\
\hline $\mathbf{o}$ & & & & & 74 & 5 & $\mathbf{I}$ & o \\
\hline $\mathbf{I}$ & 77 & 76 & 56 & 59 & 54 & 53 & 7 & 8 \\
\hline 2 & 89 & 65 & 37 & 23 & 43 & 59 & 17 & 3 \\
\hline 3 & 61 & 48 & 29 & I3 & $3 \mathrm{I}$ & 37 & 6 & 2 \\
\hline 4 & 55 & 24 & $2 I$ & 6 & 27 & 25 & II & $\mathbf{I}$ \\
\hline 5 & 47 & 24 & Io & 2 & 26 & 19 & I I & $\mathbf{I}$ \\
\hline 6 & 23 & 22 & 7 & - & I 8 & $2 \mathrm{I}$ & 3 & 2 \\
\hline 7 & 24 & I6 & 9 & & 14 & I9 & 9 & 0 \\
\hline 8 & 13 & I 5 & 5 & & Io & 18 & 4 & 2 \\
\hline 9 & 7 & 7 & 3 & & Io & I4 & 3 & 4 \\
\hline Io & 2 & 8 & o & & I I & I5 & 5 & I \\
\hline I I & o & 9 & $\mathbf{I}$ & & 9 & IO & 4 & I \\
\hline 12 & 0 & 5 & o & & 4 & 6 & 4 & 2 \\
\hline I3 & I & 5 & I & & 5 & 6 & 4 & 2 \\
\hline I 4 & - & 2 & 3 & & 9 & 3 & 5 & 2 \\
\hline I5 & & 4 & - & & 8 & 7 & 8 & 2 \\
\hline I6 & & 3 & & & 4 & 6 & 6 & 4 \\
\hline I7 & & 2 & & & 3 & 4 & 4 & 2 \\
\hline 18 & & 4 & & & 6 & 5 & 6 & I \\
\hline I9 & & I & & & 5 & I & 4 & I \\
\hline 20 & & 2 & & & 5 & $\mathbf{I}$ & 5 & 5 \\
\hline $2 \mathrm{I}$ & & $\mathbf{I}$ & & & 3 & $\mathbf{I}$ & I & 2 \\
\hline 22 & & 2 & & & 2 & 2 & 4 & 3 \\
\hline 23 & & 0 & & & 3 & $\mathbf{I}$ & o & 3 \\
\hline 24 & & o & & & o & I & 2 & 2 \\
\hline 25 & & I & & & 3 & o & 2 & 2 \\
\hline 26 & . & - & & & I & o & 3 & 2 \\
\hline 27 & & & & & 3 & I & I & o \\
\hline 28 & & & & & 2 & I & o & 2 \\
\hline 29 & & & & & 0 & o & $\mathbf{I}$ & 2 \\
\hline 30 & & & & & 0 & o & 2 & $\mathbf{o}$ \\
\hline $3 \mathrm{I}$ & & & & & 2 & I & 3 & o \\
\hline 32 & & & & & I & $\mathbf{I}$ & 3 & $\mathbf{I}$ \\
\hline 33 & & & & & o & I & $\mathbf{I}$ & o \\
\hline 34 & & & & & o & o & I & 2 \\
\hline 35 & & & & & 0 & o & 3 & o \\
\hline 36 & & & & & 0 & o & $\mathbf{o}$ & I \\
\hline 37 & & & & & 0 & $\mathbf{o}$ & I & $\mathbf{I}$ \\
\hline 38 & & & & & 0 & o & $\mathbf{o}$ & I \\
\hline 39 & & & & & o & o & o & I \\
\hline 40 & & & & & 0 & o & 2 & $\mathbf{I}$ \\
\hline $4 I$ & & & & & 0 & 0 & I & I \\
\hline 42 & & & & & 0 & o & 2 & o \\
\hline 43 & & & & & o & o & o & 0 \\
\hline 44 & & & & & o & o & 3 & I \\
\hline 45 & & & & & 0 & I & 2 & o \\
\hline $\begin{array}{l}\text { Various lengths } \\
\text { above } 45\end{array}$ & & & & & $\begin{array}{l}(2, \text { the } \\
\text { highest }\end{array}$ & 一 & (13, the & (29, the \\
\hline & & & & & being 68) & & being 88) & being I4I) \\
\hline Arithmetical & & & & & & & & \\
\hline mean. ...... & 3.506 & 4.88 & 3.236 & I.733 & 5.910 & 6.16 & I 8.05 & 29.5 \\
\hline $\begin{array}{l}\text { Standard devi- } \\
\text { ation . . . . . }\end{array}$ & $2.24 \mathrm{I}$ & $4 \cdot 54$ & $2.65 \mathrm{I}$ & I.oI 8 & 6.830 & 5.742 & I 7.86 & 31.19 \\
\hline
\end{tabular}


that the condition of no correlation between $x$ and $y$ called for by our algebraic formula is fulfilled. We may now substitute in (I2) the values of $x, y, \sigma_{x}$, and $\sigma_{y}$ for each mineral in turn and by solving the equations find the number of intercepts to be measured in each case for a probable error of I per cent. The results are shown in Table II.

TABLE II.

Number of Intercepts of Maine Granite for a Probable Error of One Per Cent.

\begin{tabular}{|c|c|c|}
\hline Mineral. & $\begin{array}{c}\text { Percentage in } \\
\text { Round Numbers. }\end{array}$ & Number. \\
\hline Quartz & $\ldots \quad 40$ & 435 \\
\hline Orthoclase & $\ldots \quad 40$ & 480 \\
\hline Oligoclase & $\ldots \quad$ I 5 & I 25 \\
\hline Biotite ... & $\ldots$ & 17 \\
\hline
\end{tabular}

To be reasonably certain that the error shall not exceed I per cent., it will be necessary to employ ( $\mathrm{I}_{3}$ ), securing results ten times those given in Table II.

The intercepts along ten parallel lines on each of two other specimens of the same granite were measured, and the arithmetical means and standard deviations of each mineral calculated. The probable errors in the mean intercepts for the new rocks and for the old rock were calculated, the probable error in a mean being 0.6745 multiplied by the standard deviation and divided by the square root of the number of measurements. By this method, the results shown in Table III. were obtained.

TABLE III.

Means and Standard Deviations of Intercepts of Three Specimens of the Same Granite.

\begin{tabular}{|c|c|c|c|c|}
\hline & & Rock I. & Rock II. & Rock III. \\
\hline \multirow[t]{2}{*}{ Quartz: } & $\begin{array}{l}\text { Mean intercept . . . . . . . . . . } \\
\text { Probable error in same. }\end{array}$ & $\begin{array}{l}3.51 \\
0.076\end{array}$ & $\begin{array}{l}3.77 \\
0.076\end{array}$ & $\begin{array}{l}2.99 \\
0.064\end{array}$ \\
\hline & Standard deviation. . . . . & $2.24 \mathrm{I}$ & 2.807 & 2.155 \\
\hline \multirow[t]{3}{*}{ Orthoclase: } & Mean intercept. & 4.87 & 5.16 & $4 \cdot 39$ \\
\hline & Probable error in same. & 0.16 & 0.17 & o.I 7 \\
\hline & Standard deviation. . . . . & 4.54 & $5 \cdot 30$ & 4.60 \\
\hline \multirow[t]{3}{*}{ Oligoclase: } & Mean intercept....... & 3.24 & 2.56 & 2.52 \\
\hline & Probable error in same. . & 0.14 & 0.10 & 0.10 \\
\hline & Standard deviation . . . . . . & 2.65 & 2.46 & 2.22 \\
\hline \multirow[t]{3}{*}{ Biotite: } & Mean intercept........... & I.73 & I. 52 & I.50 \\
\hline & Probable error in same....... & 0.068 & 0.038 & 0.057 \\
\hline & Standard deviation. . . . . . . . & $\mathbf{1 . 0 2}$ & $0.7 \times 7$ & 0.825 \\
\hline
\end{tabular}


The results are seen to be fairly concordant. They indicate that the rock is well mixed on the whole, the slight tendency to segregation of minerals observed being unimportant since all the variations obtained may be attributed to fluctuations in random sampling with the possible exception of the quartz in Rock III. and the oligoclase in Rock I. whose wider deviations may be in part due to segregation. We may therefore look upon the numbers in Table II. as fairly safe guides to the number of measurements required by rocks of this character.

D. Subsample Method.-The measurements of intercepts on each of the ten lines on each of the three rocks were kept separate, and the percentages of the various minerals for each line have been calculated and are exhibited in Table IV. Each sample has thus been divided into ro subsamples which may be used to estimate roughly the probable error in the percentage based on the entire sample, by computing the probable error in the mean of the percentages in a similar way to that in which the probable errors in the means of intercepts were obtained for Table III.

Let us illustrate by a single instance, the quartz in Rock II. The standard deviation of the ro subgroups in the table is 5.3. The probable error in the percentage based on these subgroups will therefore be $5 \cdot 3(0.6745) / \sqrt{\mathrm{IO}}=\mathrm{I}$.I. So $p$ is put down in the table as $4 \mathrm{I} .7 \mathrm{I} \pm$ I.I. The other $p$ 's shown in the table were derived in like manner.

Next let us consider how many measurements should be taken to reduce to the desired error the probable error so found. As an example, let us take the quartz in Rock III., which has a probable error of $\mathrm{I} .3$ per cent. from 557 measurements and determine how many measurements we should expect to have to take to obtain a probable error of I per cent. The probable error in a mean is inversely proportional to the square root of the number of variates. Squaring, the number becomes: (I.3/1.0 $)^{2}=$ I.69. We must therefore take 1.69 times 557 ,- or 94I measurements, -in order to expect the probable error to be reduced to I per cent.

The method of using Io subsamples to estimate the probable error in the percentages in the sample is far from an ideal method, 
TABLE IV.

Percentages of Minerals in Sub-Samples.

\begin{tabular}{|c|c|c|c|c|c|c|c|c|c|}
\hline \multirow{2}{*}{ Rock. } & \multirow{2}{*}{ Line. } & \multicolumn{2}{|c|}{ Quartz. } & \multicolumn{2}{|c|}{ Orthoclase. } & \multicolumn{2}{|c|}{ Oligoclase. } & \multicolumn{2}{|c|}{ Biotite. } \\
\hline & & $\begin{array}{l}\text { Inter- } \\
\text { cepts. }\end{array}$ & Per Cent. & $\begin{array}{l}\text { Inter- } \\
\text { cepts. }\end{array}$ & Per Cent. & $\begin{array}{l}\text { Inter- } \\
\text { cepts. }\end{array}$ & Per Cent. & $\begin{array}{l}\text { Inter- } \\
\text { cepts. }\end{array}$ & $\begin{array}{c}\text { Per } \\
\text { Cent. }\end{array}$ \\
\hline \multirow[t]{10}{*}{ I. } & $\mathbf{I}$ & 37 & $34 \cdot 3$ & 38 & $45 \cdot 5$ & $2 I$ & I 7.0 & 6 & 3.2 \\
\hline & 2 & 44 & 37.7 & 36 & 45.0 & I6 & I2.8 & 12 & 4.7 \\
\hline & 3 & 36 & 35.4 & 37 & 50.8 & I I & 7.8 & I 4 & 6.0 \\
\hline & 4 & 45 & 41.2 & 36 & $4 I .2$ & I4 & I3. 3 & 7 & $4 \cdot 3$ \\
\hline & 5 & 34 & 32.8 & 34 & 42.4 & I9 & 20.0 & I I & 4.8 \\
\hline & 6 & 49 & 42.8 & 32 & 32.6 & 24 & 20.4 & I 2 & 4.2 \\
\hline & 7 & 40 & 32.4 & $3 I$ & 46.0 & I9 & I 5.4 & I2 & 6.2 \\
\hline & 8 & $4 I$ & 37.7 & 36 & 43.7 & I4 & I3.3 & I3 & $5 \cdot 3$ \\
\hline & 9 & 37 & 37.1 & 23 & 38.7 & 26 & $22 . \mathrm{I}$ & 5 & $2 . I$ \\
\hline & IO & 36 & 31.0 & 43 & $5 I .3$ & I9 & I 2.4 & I I & $5 \cdot 3$ \\
\hline \multirow[t]{2}{*}{ Total... } & $\ldots \ldots$ & 399 & & 346 & & I 82 & & I03 & \\
\hline & $P$ & \multicolumn{2}{|c|}{$36.3 \pm 1.0$} & \multicolumn{2}{|c|}{$43.7 \pm I .2$} & \multicolumn{2}{|c|}{ I $5.29 \pm 0.89$} & \multicolumn{2}{|c|}{$4.62 \pm 0.25$} \\
\hline \multirow[t]{10}{*}{ II. } & $\mathbf{I}$ & 54 & 35.1 & 50 & $5 \mathrm{~T} . \mathrm{I}$ & $2 \mathrm{I}$ & $9 . I$ & I 5 & 4.7 \\
\hline & 2 & 63 & 38.2 & $5 I$ & $44 \cdot 7$ & 32 & I3.6 & I3 & 3.5 \\
\hline & 3 & 58 & 43.2 & 34 & $35 \cdot 5$ & 32 & I6.8 & I9 & $4 \cdot 5$ \\
\hline & 4 & 50 & 38.1 & 44 & $45 . I$ & 23 & I2.I & I 8 & $4 \cdot 7$ \\
\hline & 5 & 70 & $45 \cdot 5$ & 43 & 38.0 & 36 & I I.5 & 21 & 5.0 \\
\hline & 6 & 55 & 49.8 & 36 & 38.1 & $2 \mathrm{I}$ & 7.8 & I3 & $4 \cdot 3$ \\
\hline & 7 & 71 & 43.9 & 50 & 38.0 & 24 & I3.5 & I 8 & 4.6 \\
\hline & 8 & 78 & 39.2 & 57 & 44.9 & 24 & I 2.0 & IO & 3.9 \\
\hline & 9 & 52 & 37.7 & 40 & 47.2 & 25 & I0.0 & $2 \mathrm{I}$ & $5 . I$ \\
\hline & IO & 68 & 45.6 & 48 & 36.2 & 27 & I 5.1 & I2 & 3.1 \\
\hline \multirow[t]{2}{*}{ Total... } & $\cdots$ & $6 \mathrm{Ig}$ & & 453 & & 265 & & I 60 & \\
\hline & $P$ & \multicolumn{2}{|c|}{$4 I .7 I \pm I . I$} & \multicolumn{2}{|c|}{$4 I .82=\mathrm{I} . \mathrm{I}$} & \multicolumn{2}{|c|}{ I2.I3 $=0.57$} & \multicolumn{2}{|c|}{$4.35=0.17$} \\
\hline \multirow[t]{10}{*}{ III. } & I & 59 & 45.9 & 39 & 40.4 & I 8 & 9.2 & IO & 4.5 \\
\hline & 2 & 65 & $44 \cdot 7$ & 46 & 45.0 & IO & 8.I & 7 & 2.2 \\
\hline & 3 & 58 & $45 \cdot 7$ & 37 & 36.7 & 23 & I3.6 & IO & 4.0 \\
\hline & 4 & 69 & 49.I & 34 & 30.2 & 28 & I8.I & 7 & 2.6 \\
\hline & 5 & 42 & 37.8 & 27 & 42.1 & 19 & I6. 7 & 9 & 3.4 \\
\hline & 6 & 70 & 57.2 & 32 & 27.2 & 19 & I2.I & 7 & 3.5 \\
\hline & 7 & 47 & $44 \cdot 7$ & 27 & 35.8 & 20 & I5.3 & IO & 4.2 \\
\hline & 8 & 48 & 38.7 & $3 I$ & 40.6 & 20 & I 5.9 & IO & 4.8 \\
\hline & 9 & 55 & $35 \cdot 3$ & 30 & 42.3 & 34 & I6.6 & I 8 & 5.8 \\
\hline & IO & 44 & 38.4 & 28 & 39.4 & 26 & I8.6 & IO & 3.6 \\
\hline \multirow[t]{2}{*}{ Total... } & $\ldots \ldots$ & 557 & & $33 I$ & & 217 & & 98 & \\
\hline & $P$ & \multicolumn{2}{|c|}{$43.7 \pm \mathrm{I} .3$} & \multicolumn{2}{|c|}{$38.0 \pm 1.2$} & \multicolumn{2}{|c|}{$\mathrm{I} 4.45 \pm 0.7 \mathrm{I}$} & \multicolumn{2}{|c|}{$3.86 \pm 0.21$} \\
\hline
\end{tabular}

since with small numbers and but little knowledge of the actual distribution, the probable errors thus obtained have themselves a considerable probable error. It is therefore interesting to com- 
pare the results obtained on Rock I. by this method with those obtained on the same rock by the intercept method.

TABLE V.

Probable Error in Percentages by Two Methods.

\begin{tabular}{|c|c|c|}
\hline Mineral. & Subsample Method. & Intercept Method. \\
\hline Quartz & $\ldots \ldots .79$ & I.04 \\
\hline Orthoclase & $\ldots \mathrm{I} .2$ & I. 2 \\
\hline Oligoclase & $\ldots . .0 .89$ & 0.83 \\
\hline Biotite ... & $\ldots \ldots .25$ & 0.40 \\
\hline
\end{tabular}

It will be observed that both quartz and biotite give considerably larger probable errors by the more refined method based on the measurements of the individual intercepts than they do by that based on the measurements of subsamples. Nevertheless, the results obtained by the subsample method are near enough to those obtained by the intercept method to constitute an important indication as to the probable degree of accuracy attained.

\section{SUGGESTED PROCEDURE.}

It seems unlikely that the results obtained from the measurements of intercepts of one type of rock afford more than a general guide to what may be expected from some other type of rock. For rocks of a different type from that which we measured the following procedure is recommended.

It is desired to determine $p$ with a reasonable certainty that it is correct within $E$ per cent. Keep the measurements of intercepts in subgroups and by testing from time to time as described in section IV, $D$., ascertain when sufficient measurements have been made to predict a probable error of $E$ per cent. in the most variable mineral. Then make a frequency distribution similar to that shown in Table I. and determine whether the expected probable error has been obtained. If not, continue the measurement of intercepts until a probable error of $E$ per cent. has been secured. Compute the percentages of the various minerals indicated by these measurements.

Measure a like number of intercepts, omitting the division into 
subsamples and the making of a frequency distribution. Calculate the percentages suggested by this set of measurements There is an even chance that the most variable of these results will agree with the corresponding result in the first set of measurements within $E$ per cent., so in the long run more than half of the percentages will check at this point. Average the percentages of those minerals which check and do not measure any more intercepts to those minerals.

Make the third series of measurements on intercepts of minerals which have not checked, keeping account of the total lengths of lines in which these intercepts are included. Continue this process until all the minerals in the rock have checked within $E$ per cent.

Considerable time may be saved if it be permitted that one mineral be determined by difference. As the error in the mineral so determined will be but slightly greater than that in the minerals determined by checking, we recommend this variation of the method for general use. This means that in making the first set of measurements enough should be taken so that the second most variable mineral shall have a probable error of $E$ per cent., and that in succeeding series the measurement of intercepts of the most variable mineral may be neglected.

If this procedure had been followed in the case of the three specimens of biotite-granite from Maine, with the requirement that $E$ equal I per cent., the orthoclase would have been neglected after the first series of measurements and determined by difference at the end. The biotite in the first and second rocks would have checked within I per cent. In the third set of measurements, the oligoclase would have checked with that in the first. If measurements of a fourth sample were taken, they would be very likely to check the quartz. Even if that occurred, the chances would have been less favorable in this instance than might be expected in half of a large number of similar cases. 
VI. TIME REQUIRED FOR A DETERMINATION.

It is impossible to state exactly the time that will be required for a determination of given accuracy by the linear mensuration method since it depends upon chance. We may, however, obtain a very rough idea of the amount of time required by considering the rather unfavorable case of the Maine granite discussed in the last paragraph of the preceding section.

If the suggested procedure had been followed in the case of this rock and the quartz had checked in the fourth sample, 3,283 intercepts would have been measured. At the rate of 5 measurements per minute, a rate that can be readily attained either macroscopically or microscopically, it would take II working hours to complete these measurements. It is hardly necessary to point out that these hours should not be taken consecutively on account of the great strain on the eyes even when making measurements with the naked eye. The calculations will consume about 2 hours, bringing the total up to $\mathrm{I}_{3}$, and if it is desired to check the orthoclase an additional 3 hours will be needed, making I 6 hours in all, or say 2 working days of 8 hours each.

This may seem a long time to spend on a single determination of the relative volumes of the minerals in a rock, but with a rock of this type, even under the most favorable circumstances, we could not shorten the time to less than I day of 8 hours, while under the most unfavorable conditions the time might have to be extended to 8 days of 8 hours. Fortunately, however, more than half of any large number of determinations on rocks of this character would require less than 2 days of 8 hours.

When we consider that a chemical analysis of a rock calls for 5 days of 8 or ro hours, ${ }^{1}$ the time required for a linear determination does not seem so excessive. It is well to note in passing that while duplicate chemical analyses on the same sample may check with a high degree of accuracy, it does not follow that a second random sample of the same rock would give results in close agreement with the first. This depends upon whether a sufficiently

${ }^{1}$ H. S. Washington, "Manual of the Chemical Analysis of Rocks" (1904) 69-70. 
large original sample was taken and upon whether it was crushed to a sufficient degree of fineness before each reduction in size of sample. The easiest way to determine whether these conditions have been fulfilled is to take a second sample of similar size, reduce it in a similar manner, analyze it and decide from the deviations of the different constituents whether the sampling has been properly done. Such a procedure would practically double the time required for a chemical determination and make the time required for a linear determination seem short in comparison.

\section{SUMMARY.}

The mensuration methods are simple and direct and it has been shown that they are theoretically sound. The linear mensuration method is readily applicable both macroscopically and microscopically and has been studied in detail. Two methods of determining its degree of accuracy have been presented and a systematic procedure for making a determination has been outlined. It has been shown that the time required to determine the components of a granite rock to within I per cent. of the rock for each component will ordinarily require less than two days.

The linear mensuration method is therefore recommended for general use in the determination of the relative volumes or relative weights of the components of a rock. 